\title{
A comparative Analysis of Nonresonant Microstrip Patch-Fed Dielectric Resonator Antenna and Proximity- Fed Annular Slot Antenna
}

\author{
Dipali Gupta \\ M. Tech Scholar in Laxmi Narayan College of \\ Technology, Bhopal
}

\begin{abstract}
This paper shows the comparative analysis of a cylindrical dielectric resonator antenna (CDRA) fed by nonresonant microstrip patch and a proximity-fed planar annular slot (PPAS) antenna. The antenna array having an antenna element for higher directive gain at the center frequency 9.04 $\mathrm{GHz}$. The band-notch is detained by almost a half-wavelength split-ring parasitic element printed around the radiating patch which is excited via a proximity-fed strip line with a planning of EBG via holes. The voltage standing wave ratio (VSWR) of the annular slot antenna is less than 2.0 in the frequency band of $7.92 \mathrm{GHz}$ i.e. from 2.82 to $10.74 \mathrm{GHz}$. The PPAS antenna provides good gain flatness, high efficiency and omnidirectional field pattern over its whole frequency band and is appropriate for UWB applications. While CDRA array offer a bandwidth of $3.8 \mathrm{GHz}$ and maximum gain of $14.8 \mathrm{dBi}$ at the operating frequency
\end{abstract}

\section{Keywords}

Antenna gain, cylindrical DRA (CDRA), dielectric resonator antenna (DRA), nonresonant microstrip patch.

\section{INTRODUCTION}

The dielectric resonator antenna (DRA) has better consideration due to its pretty features as lesser size, flexible excitation methods, great temperature tolerance, etc. [1]. The DRA is excited by various feeding schemes as microstrip-line feed, conformal strip feed, aperture-coupled by microstrip line or coplanar waveguide, coaxial probe, etc. the DRA arrays also engrossed broad attention because of high gain in various communiqué schemes. There may be various shapes for the design of DRAs. The hypothetical study of first resonant modes with cylindrical dielectric resonator was presented in [2].

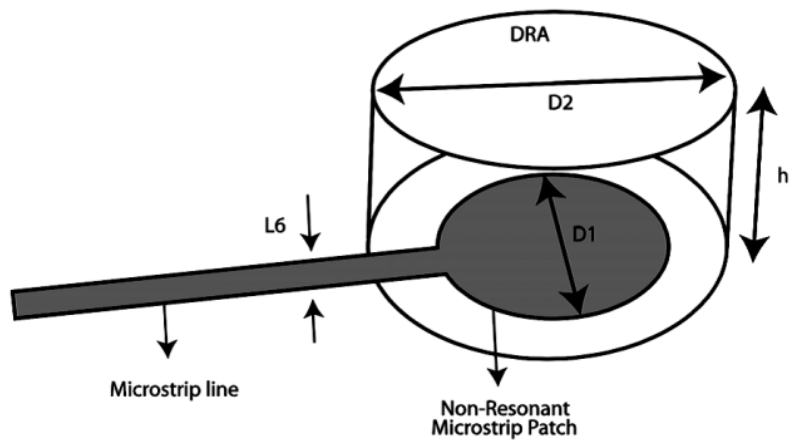

Fig 1: the CDRA element design, Substrate Length $=70$ $\mathrm{mm}$, substrate width $=60 \mathrm{~mm}, \mathrm{D} 1=4.4 \mathrm{~mm}, \mathrm{D} 2=9.525 \mathrm{~mm}$, $h=4.7 \mathrm{~mm}$, substrate thickness $=1.58 \mathrm{~mm}, \mathrm{~L} 6=0.7 \mathrm{~mm}$, microstrip line length $=27.8 \mathrm{~mm}[4]$.

\author{
Abhinav Bhargava \\ Assistant Professor in Laxmi Narayan College of \\ Technology, Bhopal
}

Mostly three of the modes, i.e., $H E M_{11 \delta}, H E M_{12 \delta}$, and $T M_{11 \delta}$, were considered for efficient radiation. The nonresonant microstrip patch appreciates a current ribbon, for the $H E M_{12 \delta}$-mode excitation to satisfy the required boundary condition in a CDRA, and simulated gain of $6.3 \mathrm{dBi}$ was stated.

In, $2 \times 2$ array of CDRA with circular-shaped nonresonant microstrip patch to excite $H E M_{12 \delta}$ mode for efficient radiation. The CDRA height has been acquired for best possible broadside radiation. The power is divided correspondingly to all the elements through the transformer of quarter-wavelength. The array yields lesser ohmic loss at higher frequencies related to a regular microstrip patch array. Therefore, it provides greater radiation efficiency as compared to a normal patch antenna array.

The antenna designs of Ultra-wideband (UWB) range are increased noticeably as the Federal Communication Commission (FCC) in USA permits the 3.1-10.6 GHz frequency band for UWB communication [3]. The practice of $5.15-5.825 \mathrm{GHz}$ frequency band that is limited by HIPERLAN/2 and IEEE 802.11a causes an interference with some UWB applications which shares the parts of similar spectrum. This is necessary to prevent such interferences in the UWB system which is done by a band-notch filter. The addition of a filter to UWB scheme raises the complexity of system.

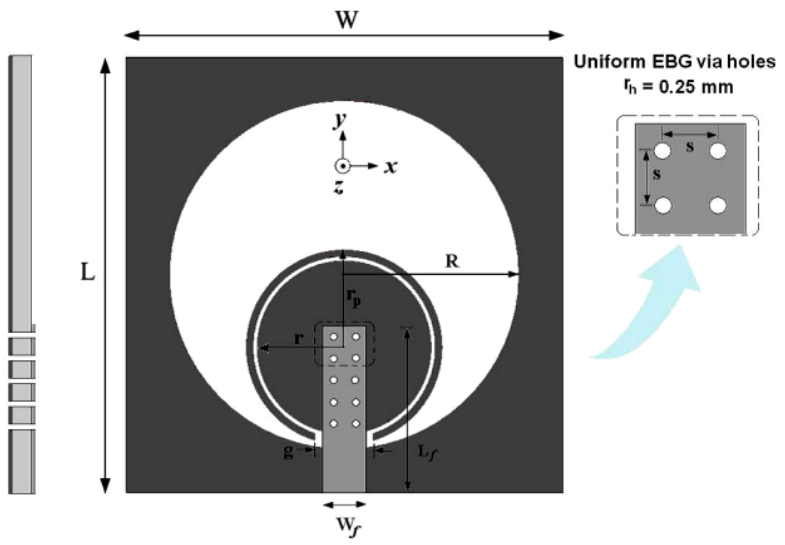

Fig 2: Planar annular slot antenna (PASA) with split-ring parasitic element $(L=30 \mathrm{~mm}, W=30 \mathrm{~mm}, R=12 \mathrm{~mm}, r p$ $=6.75 \mathrm{~mm}, \mathrm{~g}=4.0 \mathrm{~mm}, \mathrm{rh}=0.25 \mathrm{~mm}, \mathrm{~s}=1.5 \mathrm{~mm} \mathrm{r}=6$ $\mathrm{mm}, \mathrm{Lf}=11.5 \mathrm{~mm}, \mathrm{Wf}=3 \mathrm{~mm}$, ) [5].

The required frequency band-notch characteristics are provided by the UWB antenna system itself [4]-[12]. For UWB applications the simple annular slot antenna with proximity-feeding method with an organization of EBG via holes to have band-notched characteristic is adopted. At 5.51 
$\mathrm{GHz}$ a band-notch filtering is attained by introducing a splitring parasitic element about radiating patch of antenna. Details of the planar annular slot antenna (PASA) structure and design methodology are described in Section II. Design of CDRA Array antenna and characteristics are discussed in Section III. The result analysis is done in chapter IV. This work is concluded with a brief summary in Section V.

\section{PAGE SIZE PLANAR ANNULAR SLOT ANTENNA DESIGN}

The optimized planar annular slot antenna element is designed as depicted in Fig. 2. The prototype antenna is shown on a 30 (L) x $30(\mathrm{~W}) \mathrm{mm} 2 \mathrm{FR} 4$ substrate having relative permittivity 4.7, a loss tangent 0.02 , and a thickness $\mathrm{h}=1.5 \mathrm{~mm}$. A radiating circular patch of radius $\mathrm{r}=6.0 \mathrm{~mm}$ is located nonconcentrically inside a slot having radius $\mathrm{R}=12.0 \mathrm{~mm}$ etched off the ground surface. The above mentioned circular slot signifies a ground plane aperture (GPA). The centers of the circular GPA and the circular patch are on the similar vertical symmetric line of the substrate. The distance between
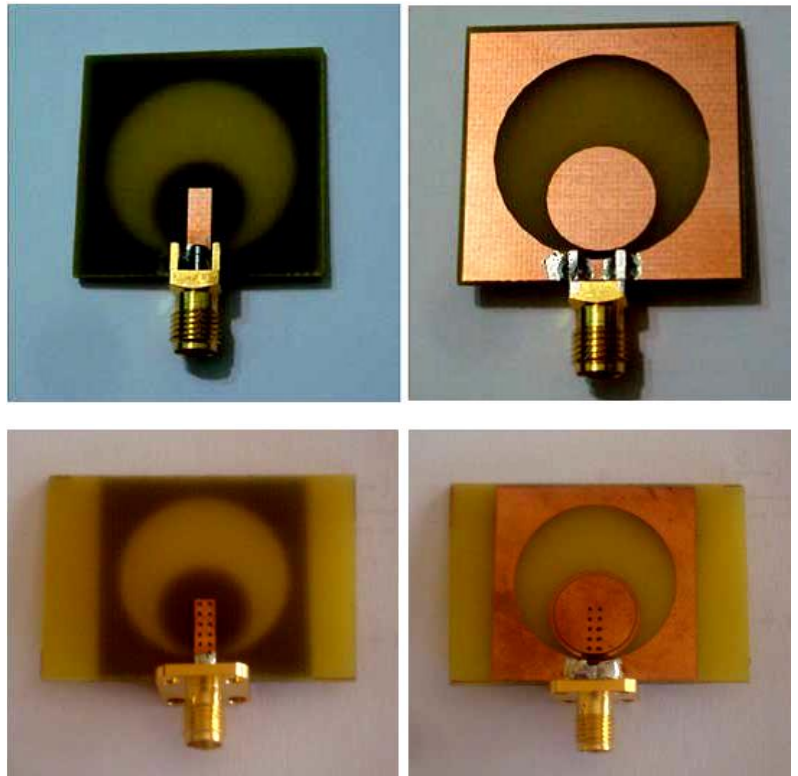

Fig 3: (a) Prototype antenna, (b) antenna with EBG via holes and split-ring parasitic element the lower verge of the circular patch and the lower verge of the circular slot is $1.0 \mathrm{~mm}$ [5].

The patch is excited via $50 \Omega$ proximity-feed microstrip line located on the opposite side of substrate, with width $W_{f}=3.0$ $\mathrm{mm}$ and length, $L_{f}=11.5 \mathrm{~mm}$ [13]. A photograph of the antenna is presented in Fig. 3(a). To improve the impedance bandwidth of the stated prototype antenna 10 circular electromagnetic band gap (EBG) via holes of radius $r_{h}=0.25$ $\mathrm{mm}$ are joining the microstrip feed-line and the radiating patch through the substrate to attain high magnetic coupling between the radiating patch and the microstrip feed line. The centers of consecutive holes having vertical distance $\mathrm{s}=1.5$ $\mathrm{mm}$. A ribbon of width $0.5 \mathrm{~mm}$ is considered about the holes to the upper, left, and right edges of microstrip line. a splitring parasitic element of external radius $r_{p}=6.75 \mathrm{~mm}$ and with uniform width of $0.5 \mathrm{~mm}$ is inserted around the patch with a uniform split-up of $0.25 \mathrm{~mm}$ between the parasitic ring and the patch to reach the band-notch performance. As presented in fig. 2 a gap $\mathrm{g}=4.0 \mathrm{~mm}$ is left between the two ends of the split-ring to fit the band-notch. An image of the implemented annular slot antenna with EBG via holes and split-ring parasitic element is shown in Fig. 3(b).

\section{CDRA ARRAY}

Firstly, a single-element of CDRA as shown in Fig. 1 has been considered on FR-4 substrate having thickness of 1.58 $\mathrm{mm}$, dielectric constant of 4.4 and loss tangent of 0.02 . The dielectric constant $\left(\varepsilon_{r}\right)$ of CDRA is 20 . The height of CDRA is obtained corresponding to extreme broadside radiation. The diameter of the nonresonant microstrip patch has been varied, and minimum input $S_{11}$ has been obtained for the diameter of $4.4 \mathrm{~mm}$ as shown in Fig. 6. A design of $2 \times 2$ antenna array with CDRA element is shown in Fig. 4.

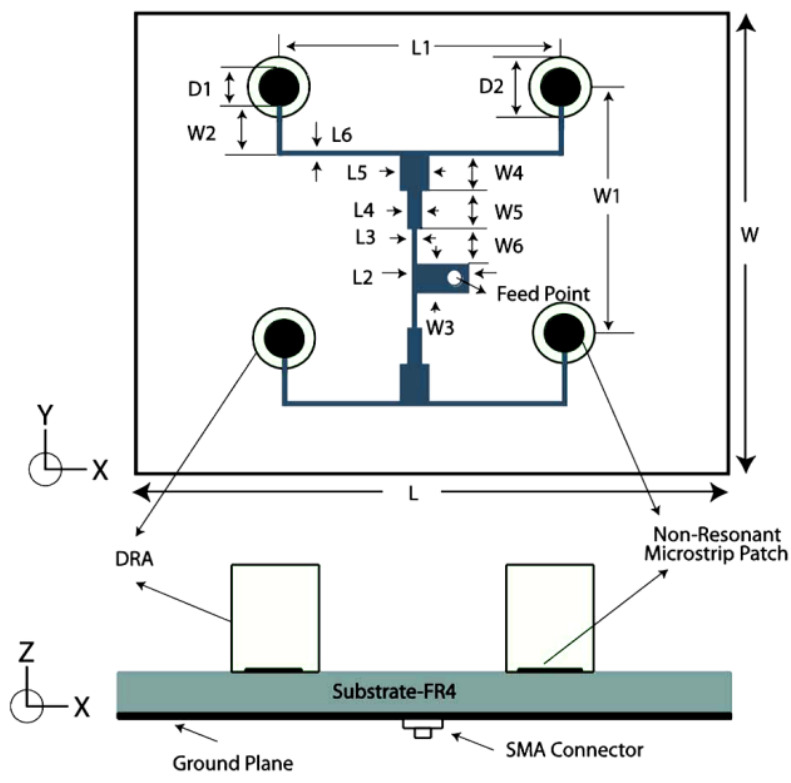

Fig 4: Top view (xy-plane) and side view (zx -plane) of the antenna array [4]

A power separator using a $\lambda / 4$ transformer is aimed to feed antenna array. There are four nonresonant circular shaped microstrip patch elements are connected to arms of the power separators.

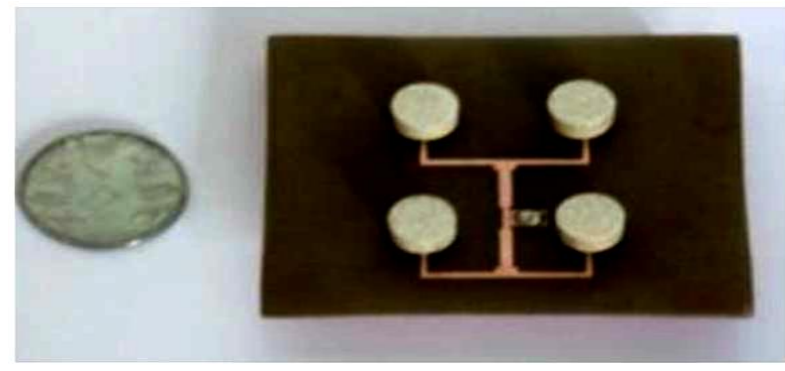

Fig. 5 Top view of the antenna array [4]

Table 1. Design Parameters of the Antenna Array [4]

\begin{tabular}{|c|c|c|c|}
\hline Parameters & $\begin{array}{c}\text { Dimension } \\
\text { in mm }\end{array}$ & Parameters & $\begin{array}{c}\text { Dimension } \\
\text { in mm }\end{array}$ \\
\hline L & 70 & W & 60 \\
\hline T & 1.58 & W1 = L1 & 23.8 \\
\hline W3 & 3.05 & W2 & 3.28 \\
\hline W4 & 1.06 & L2 & 6.35 \\
\hline L3 = L6 & 0.7 & W6 & 3.1 \\
\hline L4 & 1.61 & W5 & 8.03 \\
\hline D1 & 9.525 & D2 & 4.4 \\
\hline
\end{tabular}


The design parameters of the CDRA array are given in Table I. A prototype array is shown with Emerson \& Cuming Eccostock HIK material. The images of the fabricated CDRA array are shown in Fig. 5.

\section{RESULTS AND DISCUSSIONS}

The CDRA element resonates at $9.08 \mathrm{GHz}$ get through the observation that with it's to $H E M_{12 \delta}$ mode. The simulated resonant frequency of the antenna array is $9.04 \mathrm{GHz}$.

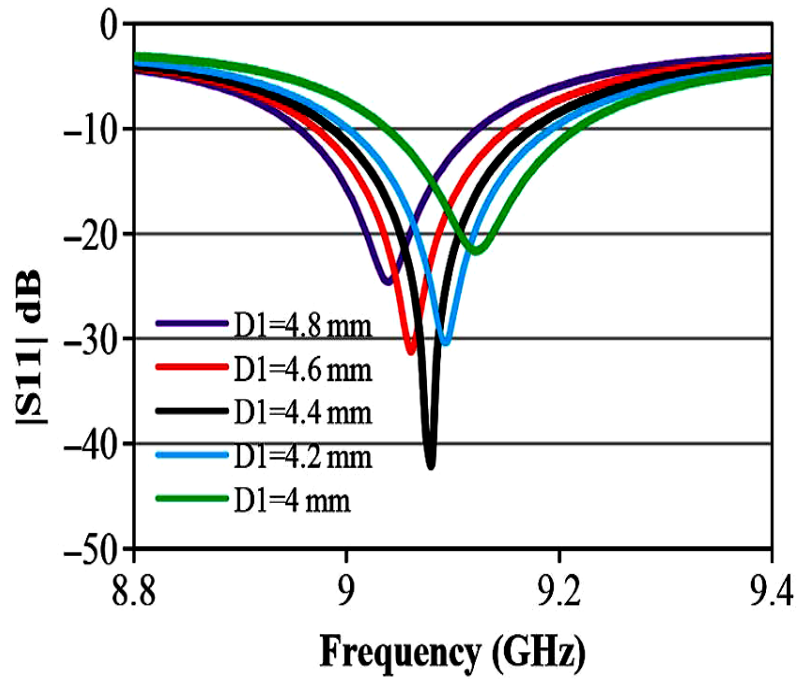

Fig. 6 Simulated S11 of the single-element CDRA for different values [4].

The S11 parameter with different Diameter D1 plotted as shown in fig. 6 . The $\mathrm{D} 1=4.4 \mathrm{~mm}$ provides the greater depth in the result.

While the result of the planer annular slot with split ring as discussed further. The VSWR characteristics are dignified with an Agilent HP8719 network analyzer. Fig. 7 illustrates the measured and simulated VSWR parameter for optimized dimensions with different cases of antenna design; with the split-ring parasitic element and with and without the EBG via holes. The measured data and the simulated results are agrees over the frequency band of interest.

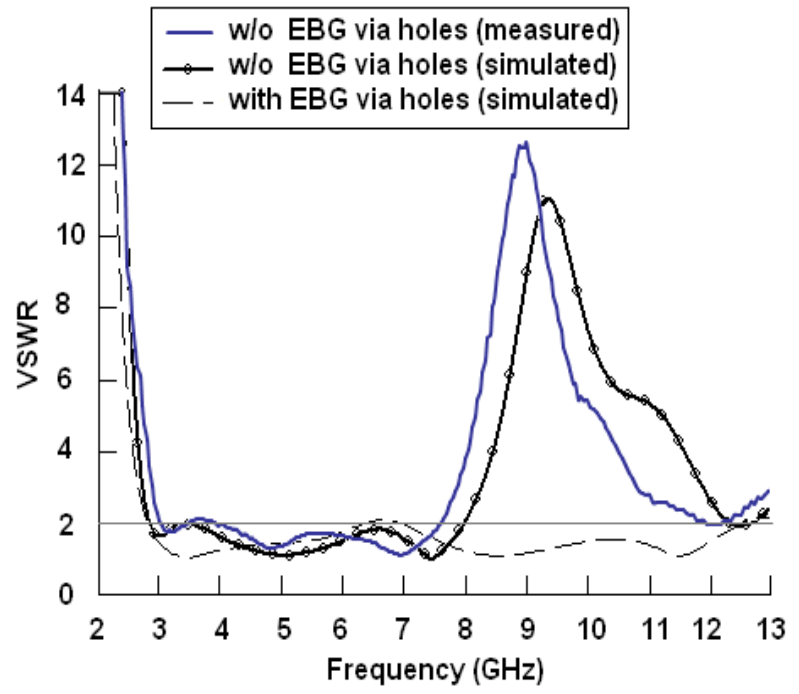

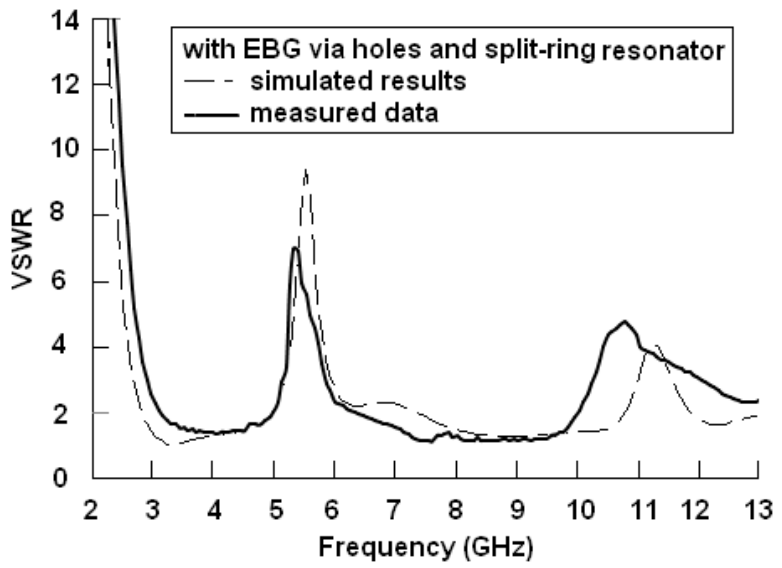

Fig. 7 The measured and simulated VSWR parameter versus frequency for the PPAS antenna, (a) With and without EBG via holes. (b) With EBG via holes and splitring parasitic constituent [5].

The VSWR parameter of the prototype antenna ranges from 2.85 to $7.95 \mathrm{GHz}$ for $V S W R \leq 2$. It seems that, the bandwidth of the PPAS antenna is more enhanced by using the EBG via holes which ranges from 2.85 to beyond $14 \mathrm{GHz}$ for $V S W R \leq 2$ that fulfil the UWB spectrum requirement.

Table 2. Comparative Analysis of Gain and Bandwidth

\begin{tabular}{|c|c|c|}
\hline Method & $\begin{array}{c}\text { CDRA antenna } \\
\text { [4] }\end{array}$ & $\begin{array}{c}\text { PPAS antenna } \\
\text { [5] }\end{array}$ \\
\hline Bandwidth & $3.8 \mathrm{GHz}$ & $7.92 \mathrm{GHz}$ \\
\hline Gain $(\mathrm{dBi})$ & 14.8 & 6 \\
\hline
\end{tabular}

Also, Fig. 7 shows that the split-ring parasitic element attains a sharp band rejection at $5.51 \mathrm{GHz}$ frequency that is appropriate to elude a frequency interference with the existed narrowband facilities such as HIPERLAN/2 and IEEE 802.11a. The table 2 describes the comparative results of CDRA and PPAS antenna.

\section{CONCLUSION}

The CDRA antenna is a technique of increasing gain of the antenna with a nonresonant microstrip patch. The measured 14.8-dBi gain found for the CDRA antenna. It is used in applications, where high-gain and narrow bandwidths are very much needed in the noisy and congested spectrum surroundings. A simple project of a band-notched UWB PASA with proximity-fed technique has been described. Electromagnetic Band Gap (EBG) via holes imprinted feeding line is used to improve the input impedance of antenna at higher frequency bands. Band-notched characteristic is attained by split-ring parasitic element around the patch. The PASA antenna has a frequency band of $2.82-10.74 \mathrm{GHz}$ for VSWR less than 2.0 with a rejection band at $5.51 \mathrm{GHz}$, which is complement with the IEEE 802.11a and HIPERLAN/2 services. The outcomes show that the PASA design with a band-notch function offers sufficient antenna recitals such as, high gain wide impedance bandwidth, appropriate band rejection and omnidirectional radiation pattern.

\section{REFERENCES}

[1] K. M. Luk and K. W. Leung, Dielectric Resonator Antennas. Baldock, England: Research Studies Press, 2003.

[2] A. W. Glisson, D. Kajfez, and J. James, "Evaluation of modes in dielectric resonators Using a surface a surface integral equation formulation," IEEE Trans. Microw. 
Theory Tech., vol. MTT-31, no. 12, pp. 1023-1029, Dec. 1983.

[3] FCC, "Federal Communications Commission Revision of part 15 of the Commission's Rules Regarding UltraWideband Transmission System," First Report and Order FCC, 02.V48, 2002.

[4] B. Rana and S. K. Parui, "Nonresonant Microstrip PatchFed Dielectric Resonator Antenna Array" IEEE ANTENNAS AND WIRELESS PROPAGATION LETTERS, VOL. 14, 2015.

[5] E. E.M. Khaled, A.A. R. Saad and D. A. Salem "A Proximity-Fed Ultra-Wideband Annular Slot Antenna with Band-Notch Characteristics via a Split-Ring Parasitic Element" EuCAP 2012.

[6] A. Kerkhoff, and H. Ling, "Design of a planar monopole antenna for use with ultra-wideband (UWB) having a band-notched characteristic," in Proc. IEEE AP-S Int. Symp. Dig., Columbus, OH, June 2003, vol. 1, pp. 830833.

[7] E. S. Angelopouslos, A. Z. Anastopoulos, D. I. Kaklamani, A. A. Alexandridis, F. Lazarakis, and K. Dangakis, "Circular and elliptical CPW-fed slot and microstrip-fed antennas for ultrawideband applications," IEEE Antennas Wireless Prop. Lett., vol. 5, no. 1, pp. 294-297, 2006
[8] J. Kim, C. S. Cho and J. W. Lee, "5.2 GHz notched ultrawideband antenna using slot-type SRR," Electron. Lett., vol. 42, no. 6, pp. 315- 316, March 2006.

[9] W. Choi, K. Chung, J. Jung, and J. Choi, "Compact ultrawideband printed antenna with band-rejection characteristic," Electron. Lett., vol. 41, no. 18, pp. 990991, Sep. 2005.

[10] J. Qiu, Z. Du, J. Lu, and K. Gong, "A band-notched UWB antenna," Microw. Opt. Technol. Lett., vol. 45, no. 2, pp. 152-154, April 2005.

[11] R. Chair, A. A. Kishk, and K. F. Lee, "Ultrawide-band coplanar waveguide-fed rectangular slot antenna," IEEE Antennas Wireless Prop. Lett., vol. 3, no. 1, pp. 227-229, 2004.

[12] A. A. Kalteh, R. Fallahi, and M. G. Roozbahani, "5-GHz band-notched UWB elliptical slot antenna fed by microstrip line," in Proc. Med. Microw. Symp., MMS 2010, Guzelyurt, Aug. 2010, pp. 444-447.

[13] A. A. R. Saad, E. E. M. Khaled, and D. A. Salem, "Novel design of proximity-fed ultra-wide band annular slot antenna," Proc. Prog. In Electro. Res. Symp., PIERS 2011, Suzhou, China, Sep. 2011, pp. 1429- 1433. 